\title{
AN AUTOMATED PROCEDURE FOR SELECTING PROJECT MANAGERS IN CONSTRUCTION FIRMS
}

\author{
Fateme Jazebi ${ }^{1}$, Abbas Rashidi ${ }^{2}$ \\ ${ }^{1}$ Payame Noor University, Ahvaz, Iran \\ ${ }^{2}$ School of Civil and Environmental Engineering, Georgia Institute of Technology, Atlanta, GA, USA; \\ ${ }^{2}$ Department of Civil Engineering, Islamic Azad University, Semnan Branch, Iran \\ E-mails: ${ }^{1}$.jazebi@gmail.com; ${ }^{2}$ rashidi@gatech.edu (corresponding author) \\ Received 06 Dec. 2011; accepted 12 Mar. 2012
}

\begin{abstract}
Selecting a suitable project manager for construction projects is one of the most important decisions made by construction firms. In the traditional approach, interviews are conducted by senior managers of the company, who consider the project requirements and the candidates' capabilities. However, interviewing candidates is usually time consuming and there is the risk of impaired judgment, leading to human error. Decision-making support systems are therefore very useful. In previous work, the authors proposed a fuzzy system to address the issues described above (Rashidi et al. 2011). In this paper, a simpler robust model is presented. The advantages of this new model lie in its simplicity and the fact that it is not necessary to consider many criteria in the selection procedure when using this model. This model only requires 15 fields of candidate information. In the development of this model, the first step is construction of an initial fuzzy model based on all the criteria that may be considered when selecting a project manager. The significance of the coefficients of the criteria are then determined. In the next step, the model is optimized by changing the number of fuzzy rules and reducing the number of criteria. Finally, the most appropriate model is chosen on the basis of the least number of criteria required to obtain accurate results. To show the model's capability, it is used in real interviews. The obtained results indicate the high accuracy of the model in predicting the output, that is, the best candidate in the interviews.
\end{abstract}

Keywords: construction project manager, fuzzy rules, criteria, input and output data, fuzzy curves.

\section{Introduction}

In recent years, construction projects have become very complicated technically. The construction project manager usually plays a major role in a project's success. They make most of the important decisions during a project. The selection of a project manager is therefore one of the most significant decisions for construction companies to make. Numerous problems can arise if an unsuitable manager is selected for a construction project.

In the last two decades, many researchers have been exploring the general skills that a project manager should possess, as well as those needed to succeed, and the criteria for the selection of project managers.

Berger (1996) highlighted the growing need for civil engineers with management skills and, perhaps, advanced degrees in engineering management. Perini listed the primary qualities of a successful construction project manager as follows: a high level of technical skill; diligence; and the ability to manage the executive team, communicate effectively, pay attention to the client's demands, prioritize, perform under pressure, ask the right questions, and take responsibility and the necessary risks to achieve goals (Liao 2007). Meredith et al. (1995) classified the skills required by a project manager into six distinct groups: communication, organizational, team- building, leadership, coping, and technological. According to Goodwin (1993), conceptual, technical, negotiation, and human resource skills are the four main skills that a project manager should possess. Ogunlana et al. (2002) believed that conceptual, human resource, negotiation, and technical skills are the most essential skills for a project manager. Sunindijo et al. (2007) studied emotional intelligence (EI) in the context of project manager selection. The results of these studies revealed that EI is beneficial to both the individual and the organization. Pheng and Chuan (2006) identified the factors that effectively influence the performance of a project manager in the private and public sectors. Dolfi and Andrews (2007) studied the personality characteristics of project manager and formulated a conclusive understanding of the motivations of project managers, especially concerning their work environment. A large number of studies have been conducted on the characteristics and responsibilities of project managers; however, only a few of them deal with the selection of project managers. The traditional method for selecting a project manager for a construction firm is to choose the best candidate after interviewing the potential ones. The interview is usually conducted by the construction firm's top managers. This method, however, has two major problems: 
1) Interviewing is usually time-consuming, particularly if there are many candidates. There are also time constraints because the construction firm's managers are usually very busy, and they are likely to have limited time. In some cases, it is impossible to interview all the candidates, and, as a result, some suitably qualified candidates may be overlooked;

2) Decision making by humans is usually fraught with error and personal judgment. Additionally, it is possible that the decision maker (interviewer) does not have enough experience to select the most suitable individual and his/her decision making may not be accurate.

Over the past two decades, much research has been carried out on various applications of fuzzy logic for decision making in the construction area.

We have proposed a fuzzy system for solving the problem of selecting project managers in construction companies (Rashidi et al. 2011). The selection process in this system requires a large number of criteria (23 criteria). Usually, it is difficult to consider and investigate so many criteria in the selection process. On the other hand, not considering some of the criteria may reduce the accuracy of the selection process.

In this article, two factors - the reduced number of required criteria in project manager selection and the acceptable range of accuracy in predicting results - are considered, and an optimized fuzzy system for the selection process in construction firms is presented. Toward this end, first, all possible criteria for the selection of a project manager were identified and an initial fuzzy expert system was developed on the basis of these criteria. The dataset required to develop and test the system was obtained from a number of interviews conducted by the senior managers of a number of major construction firms in Iran. More detailed information on the generation of the dataset can be found in Rashidi et al. (2011). Next, the importance of each criterion was determined quantitatively using a novel method, that is, the fuzzy curves method. In this way, the effects of changing the number of fuzzy rules and of eliminating a number of less important criteria were evaluated, and an optimized model that considers the least number of required criteria and gives an acceptable level of accuracy was selected. This optimized model was used in real interviews in a major construction firm. The results obtained will be compared with the results of traditional real interviews.

The rest of this paper is structured as follows: in section 2, the general structure of fuzzy expert systems is briefly described. In section 3 , the general process for the development of a fuzzy system for solving the problem of selecting project managers in construction firms is presented. Section 4 contains the necessary steps for optimizing the initial fuzzy system, and describes the procedure for testing and validating the proposed model using test data. In section 5, the application of the proposed model in real interviews, which were conducted in a major construction firm, is shown. In the final section, conclusions are drawn and discussed.

\section{Fuzzy systems}

A fuzzy system is formed by input and output fuzzy sets assigned over the system input and output variables, and accumulated fuzzy rules. The relationships between the input and the output variables are represented by means of fuzzy IF-THEN rules of the following general form (Karaboga et al. 2008): "IF antecedent proposition, THEN consequent proposition".

The most significant advantage of using this linguistic description is that no prior knowledge about the system under study is initially used to formulate the rules, and the fuzzy system is constructed from data (Karaboga et al. 2008).

Generally, creating a fuzzy system consists of two basic steps:

I. For each variable input or output, a set of fuzzy sets must be defined. Each fuzzy set is itself defined using a fuzzy membership function. A membership function defines the degree to which the value of a variable belongs to the group and is usually a linguistic term such as "high" or "low." The quantitative value of the membership function varies from 0 to 1 (Plebankiewicz 2009).

For example, $\mu_{i j}$ is the $j^{\text {th }}$ membership function of the $i^{\text {th }}$ input variable $\left(x_{i}\right)$ and defines the $j^{\text {th }}$ linguistic term for this input variable $\left(A_{i j}\right)$; $\tau_{\mathrm{k}}$ is the $k^{\text {th }}$ membership function of the output (y) and defines its $k^{\text {th }}$ linguistic term $\left(\mathrm{B}_{k}\right)$. A membership function is defined by its shape (type) and parameters. In the case of fuzzy systems, standardized functions are usually used.

II. Statements, or rules, are defined so that they relate the membership functions of each variable to the result, normally through a series of IF-THEN statements (Radziszewska-Zielina 2011). For example, in the context of problems in project manager selection, one rule would be as follows: IF the language ability of the candidate is low (linguistic term $A_{11}$, represented by a membership function $\mu_{11}$ ), and the quality of the university where the candidate studied is low (linguistic term $\mathrm{A}_{21}$, represented by a membership function $\mu_{21}$ ) (condition), THEN the score of this candidate (conclusion) is low (linguistic term $\mathrm{B}_{1}$, represented by a membership function $\tau_{1}$ ) (Torno et al. 2011).

The rule is stated as follows:

IF $x_{1}$ is $A_{11}$ and $x_{2}$ is $A_{21}$, THEN y is $B_{1}$.

In using the system, inputs are given to the system and an output is obtained. Further information can be found in Antonelli et al. (2009), Torno et al. (2011) and Du et al. (2008).

\section{The initial fuzzy system for project manager selection}

\subsection{Gathering historical data}

The first step in the construction of the fuzzy system is to determine the related criteria and sub-criteria for project manager selection. In order to do this, all criteria that may be considered by the senior managers of construction firms for project manager selection should be determined (Torfi, Rashidi 2011). 
Table 1. Criteria and sub-criteria for selection of project managers

\begin{tabular}{|c|c|c|c|}
\hline No. & & Criterion & Possible options \\
\hline 1 & \multirow{8}{*}{ 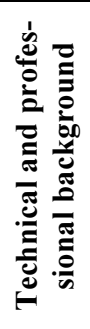 } & Years of experience & $0-45$ years \\
\hline 2 & & Years of management experience & $0-45$ years \\
\hline 3 & & Years of experience with current employer & $0-45$ years \\
\hline 4 & & Years of experience in similar project fields & $0-45$ years \\
\hline 5 & & Years of experience working with project owner & $0-45$ years \\
\hline 6 & & Years of experience in similar project environments & $0-45$ years \\
\hline 7 & & Share holder or board member of the company? & Yes-No \\
\hline 8 & & Quality assessment of previous projects & $0-100$ points \\
\hline 9 & \multirow{6}{*}{ 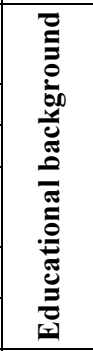 } & Major & $\begin{array}{l}\text { Mechanical Engineering - Civil Engineering - } \\
\text { Chemical Engineering - Electrical Engineering - Other }\end{array}$ \\
\hline 10 & & $\begin{array}{ll} & \text { Degree } \\
\end{array}$ & $\mathrm{BS}-\mathrm{MS}-\mathrm{PhD}$ \\
\hline 11 & & Quality of the university where the applicant graduated & $0-100$ points \\
\hline 12 & & Specialization & $\begin{array}{c}\text { Design - Construction - Supervision - Management - } \\
\text { Other }\end{array}$ \\
\hline 13 & & Continual professional development & $0-200 \mathrm{~h}$ \\
\hline 14 & & General communication skills in English & $0-100$ points \\
\hline 15 & \multirow{4}{*}{ 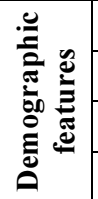 } & Gender & Male-Female \\
\hline 16 & & Age & $25-70$ years \\
\hline 17 & & Physical and mental abilities & Healthy-Unhealthy \\
\hline 18 & & Physical appearance & $0-100$ points \\
\hline 19 & \multirow{5}{*}{ 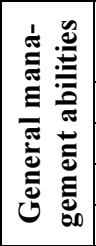 } & $\begin{array}{l}\text { Human resource management abilities (number of } \\
\text { employees working under applicant's supervision) }\end{array}$ & $0-500$ persons \\
\hline 20 & & Communication skills & $0-100$ points \\
\hline 21 & & Sound decision making under pressure & $0-100$ points \\
\hline 22 & & Work performance & $0-100$ points \\
\hline 23 & & Project condition assessment and prediction & $0-100$ points \\
\hline
\end{tabular}

To determine the necessary criteria for selection of qualified construction project managers, a questionnaire was sent to the senior managers of 18 large companies involved in different areas of construction e.g. oil and gas, roads and highways, and residential construction projects. These managers were requested to determine all the criteria they consider in the procedure of selecting a construction project manager. Based on the opinions of these experts, 23 criteria were determined and divided into four groups (Table 1).

The next step in preparing fuzzy rules is to collect historical data regarding the fuzzy system's input and output. In this study, as in the authors' previous research, the data were gathered from 46 interviews previously conducted over a two-year period by the senior managers of a number of major construction firms in Iran. All the interviews were conducted by the companies' chief officers, as they were considered to be the people best qualified to make hiring decisions. They used the abovementioned 23 criteria for the evaluations. The scores assigned to each candidate for each criterion and the total score of each candidate - which is the basis on which the best-qualified candidate will be selected - were identified by these experts. In many instances, a scale of 0 to 100 was used to evaluate qualitative criteria; each candidate received a rating on the basis of the experts' opinions. It should be mentioned that these evaluations do not require a high level of accuracy; the ability to work with such ambiguity and lack of precision are features of fuzzy systems.

On the basis of the collected data, the system outputs and inputs were classified. Inputs were derived after comparing two candidates' features for each criterion, and output was the result of comparing the total point scores of these two candidates. Obviously, in cases where the output rate was greater than 1, the first candidate was considered to be better than the second one, and vice versa. The candidates were ranked, and Table 1 provides excerpts of the interviews and information vis-à-vis defined inputs and outputs. The number of records in the input-output data was 262; of these, 200 records were used to develop the system and 62 were used to analyze and validate it.

\subsection{Preparation of the initial fuzzy system}

Using MATLAB, one fuzzy rule was developed for each training datum. A fuzzy rule is developed for each datum by including a number of inputs and one output. The appropriate membership function for criteria for which there were multiple answers was either triangular or trapezoidal; for the remaining criteria, the appropriate membership function was Gaussian functions because they can approximate almost all other types of membership functions by changing the parameters shown in Eq. (1) (Lee, Pan 2009): 


$$
\delta=\exp \left(-\frac{(x-c)^{2}}{2 \sigma^{2}}\right)
$$

where: $\delta$ is the degree of membership (membership value); $c$ is the center of the membership function; and $\sigma$ is the width of the membership function (standard deviation), which can be calculated according to Eq. (2) (Chao et al. 1996):

$$
\sigma_{i j}=\frac{\max \left\{\left|c_{i j}-c_{i R}\right|\left|c_{i j}-c_{i L}\right|\right\}}{\sqrt{\ln \lambda_{i} \mid}},
$$

where: $A_{i j}$ is the $j^{\text {th }}$ fuzzy membership function of $i^{\text {th }}$ variable; $\sigma_{i j}$ is the width of $A_{i j} ; c_{i j}$ is the center of $A_{i j}$; $c_{i R}$ is the center of fuzzy membership function, which is on the right side of $A_{i j}$ and is closest to it; $c_{i L}$ is the center of fuzzy membership function, which is on the left side of $A_{i j}$ and is closest to it; $\lambda_{I}$ is the overlapping factor of $i^{\text {th }}$ variable $\left(0<\lambda_{i}<1\right)$.

However, in cases where the sub-criterion (input) is a multiple-choice option (like educational level), the quantity $c$ is low. In these cases, a Gaussian membership function cannot be used; instead, a triangular membership function can be used. Each quantity has a triangular membership function.

As an example, three possible membership functions for the $7^{\text {th }}$ criterion are depicted in Fig. 2. For this criterion, for the statement "yes", the value is 2 , and for the statement "no", the value is 1 . There are therefore three options, i.e., $2 / 1=2 ; 2 / 2=1$, and $1 / 2=0.5$ (Fig. 1).

The fuzzification rules were defined on the basis of the historical data. In this case, $\lambda=0.5$ for all Gaussian membership functions.

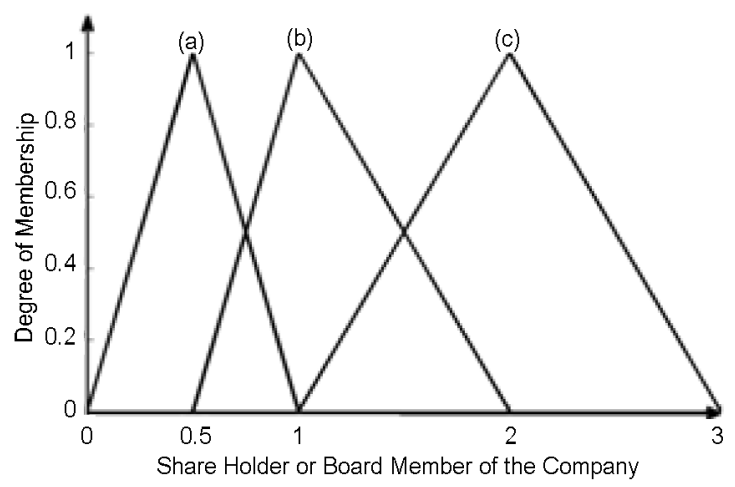

Fig. 1. Triangular membership functions of "share holder or board member of the company" sub-criterion $(a)-c=0.5$, (b) $-c=1,(c)-c=2$

\section{Simplification of the initial system using trial and error}

One of the most important motivations for building up a fuzzy system is to let users gain a deeper insight into an unknown system through easily understandable fuzzy rules (Wang et al. 2005). Fuzzy systems can be interpreted for modeling unknown nonlinear environments (Jin
2000). Interpretability is a very important property, and those traditional training methods for extracting fuzzy rules that suffer from lack of interpretability have an unnecessary number of rules (Eftekhari et al. 2008). Accordingly, several studies on the interpretability of fuzzy systems in different fields have been carried out (Ishibushi et al. 2001; Liang, Pedrycz 2009). In this paper, a novel and efficient approach is presented for constructing a fuzzy system that considers both accuracy and interpretability. An appropriate approach, using a similarity approach, has been applied to simplify the fuzzy system using similarity analysis.

System simplification was carried out using the following two procedures:

1. Combining similar rules;

2. Removing insignificant inputs.

By performing these procedures, a compact rulebased system with low complexity and high accuracy can be achieved.

\subsection{Combination of similar fuzzy rules}

Constructing a system using data may result in a number of initial membership functions, some of which are similar to each other and which therefore result in some redundant rules. A rule is redundant when it does not alter the rule base (Dubois et al. 1997). Redundant rules decrease the system's ability to interpret, and therefore, similar rules should be combined (Du et al. 2008).

The concept of the redundancy of fuzzy rules can be expressed by measuring the similarity of fuzzy sets of inputs and outputs (Castellano et al. 2002; Guillaume 2001). The similarity between two fuzzy sets is the degree to which the fuzzy sets are equal (Setnes et al. 1998). There are a number of definitions of similarity measures (Jin et al. 1999; De Baets et al. 2009). In this study, the similarity measure proposed by Jin (2000) has been used:

$S(A, B)=\frac{M(A \cap B)}{M(A \bigcup B)}=\frac{M(A \cap B)}{M(A)+M(B)-M(A \cap B)}$,

where: $M(A)$ is the cardinality of the fuzzy set $A$, and $\cap$ and $U$ are the intersection and union operators, respectively. The cardinality of the fuzzy set $A$ is expressed by Jin et al. (1999):

$$
M(A)=\int_{-\infty}^{+\infty} \mu_{A}(x) d x .
$$

To determine whether two fuzzy rules should be combined, the degree of similarity of the fuzzy rules should be determined (Chao et al. 1996). If the similarity measure of two fuzzy rules is greater than a given threshold, then these two fuzzy rules should be combined to generate a new rule. In order to combine two fuzzy rules and obtain a new one, the input and output membership functions of two of the initial fuzzy rules should be combined. If $c_{1}$ and $c_{2}$ are the centers and $\sigma_{1}$ and $\sigma_{2}$ are the widths of the initial two fuzzy sets, then the center and width of the new fuzzy set can be determined according to Eqs (5) and (6) (Eftekhari et al. 2008): 


$$
\begin{gathered}
c_{\text {new }}=\frac{\sigma_{1} c_{1}+\sigma_{2} c_{2}}{\sigma_{1}+\sigma_{2}} ; \\
\sigma_{\text {new }}=\frac{\sigma_{1}+\sigma_{2}}{2} .
\end{gathered}
$$

If the initial membership functions are triangular with the parameters $\left(a_{1}, b_{1}, c_{1}\right)$ and $\left(a_{2}, b_{2}, c_{2}\right)$, the parameters of a new membership function can be determined according to Eqs (7-9):

$$
\begin{gathered}
a_{\text {new }}=\min \left(a_{1}, a_{2}\right) ; \\
b_{\text {new }}=\frac{b_{1}+b_{2}}{2} ; \\
c_{\text {new }}=\max \left(c_{1}, c_{2}\right) .
\end{gathered}
$$

The procedure of combinig two fuzzy sets is shown in Fig. 2.

In the process of combining fuzzy rules, redundant rules may be eliminated from the rule base. At each iteration, the two rules whose similarities exceed the threshold should be combined. The rules obtained from these combinations are candidates for combination in the next iteration. The membership functions of these rules obtained by combination should therefore be assigned more weight in the merging process. More detailed information can be found at Paiva and Dourado (2004). In this study, five thresholds for the similarity measure of fuzzy rules $(0.1$, $0.09,0.08,0.07$, and 0.06) were utilized. Hence, after simplifying the initial system, five systems with a diffe- rent number of fuzzy rules $(71,62,52,48$, and 43$)$ were constructed.

\subsection{Determining the most important criteria}

In order to simplify the system, the importance of each sub-criterion should be determined, and insignificant criteria should be eliminated from the system so that the performance of the system is not affected. A precise fuzzy system is expected to accurately determine the most suitable person in a pair-wise comparison. In other words, for an actual output greater than 1, the system output should be greater than 1 , and vice versa.

To rank the inputs (sub-criteria) according to their significance, fuzzy curves are plotted for all input variables. For each input variable $x_{i}(i=1,2,3, \ldots, n=23)$, the $m$ data points in the $x_{i}-y$ space are available. For every point in the $x_{i j}-y_{j}$ space $(j=1,2,3, \ldots, m=100)$, a fuzzy membership function $\varphi_{j k}$ and, consequently, a fuzzy membership value $c_{j}\left(x_{i}\right)$, can be calculated using the following formulas (Chaturvedi et al. 2009):

$$
\begin{gathered}
\phi_{j k}\left(x_{i}\right)=\exp \left(-\left(\frac{x_{i j}-x_{i k}}{b}\right)^{2}\right) ; \\
c_{j}\left(x_{i}\right)=\frac{\sum_{k=1}^{m} \varphi_{j k}\left(x_{i}\right) \cdot y_{k}}{\sum_{k=1}^{m} \varphi_{j k}\left(x_{i}\right)} .
\end{gathered}
$$
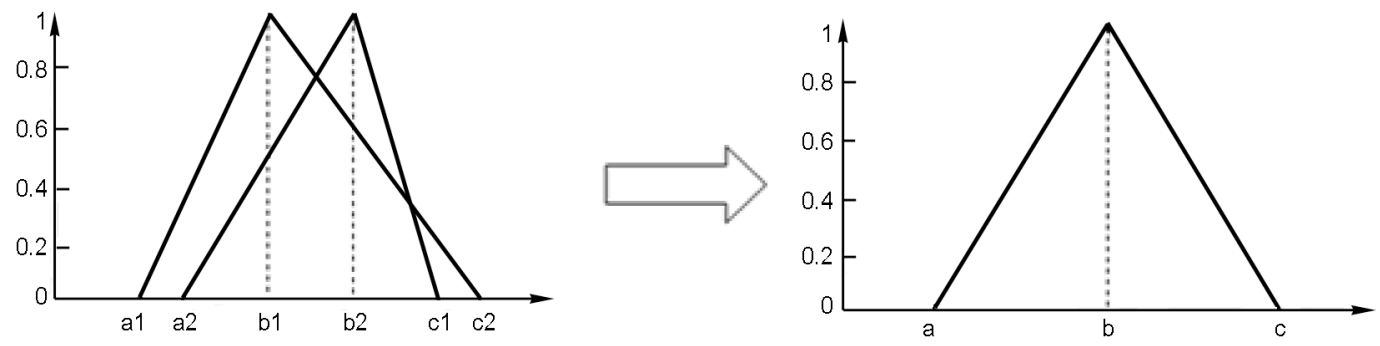

$$
a_{\text {new }}=a_{1}, \quad b_{\text {new }}=\frac{b_{1}+b_{2}}{2}, \quad c_{\text {new }}=c_{2}
$$
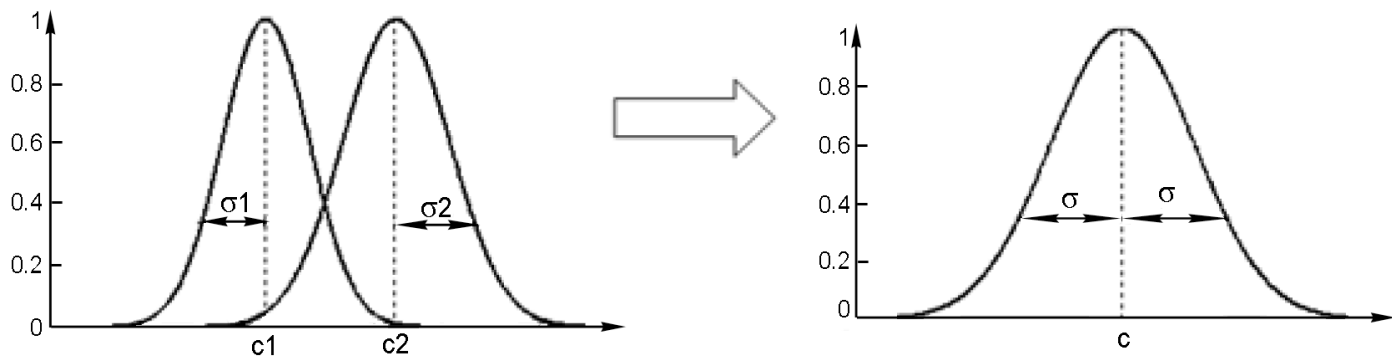

$$
c_{\text {new }}=\frac{\sigma_{1} c_{1}+\sigma_{2} c_{2}}{\sigma_{1}+\sigma_{2}}, \quad \sigma_{\text {new }}=\frac{\sigma_{1}+\sigma_{2}}{2}
$$

Fig. 2. Integration of fuzzy sets 

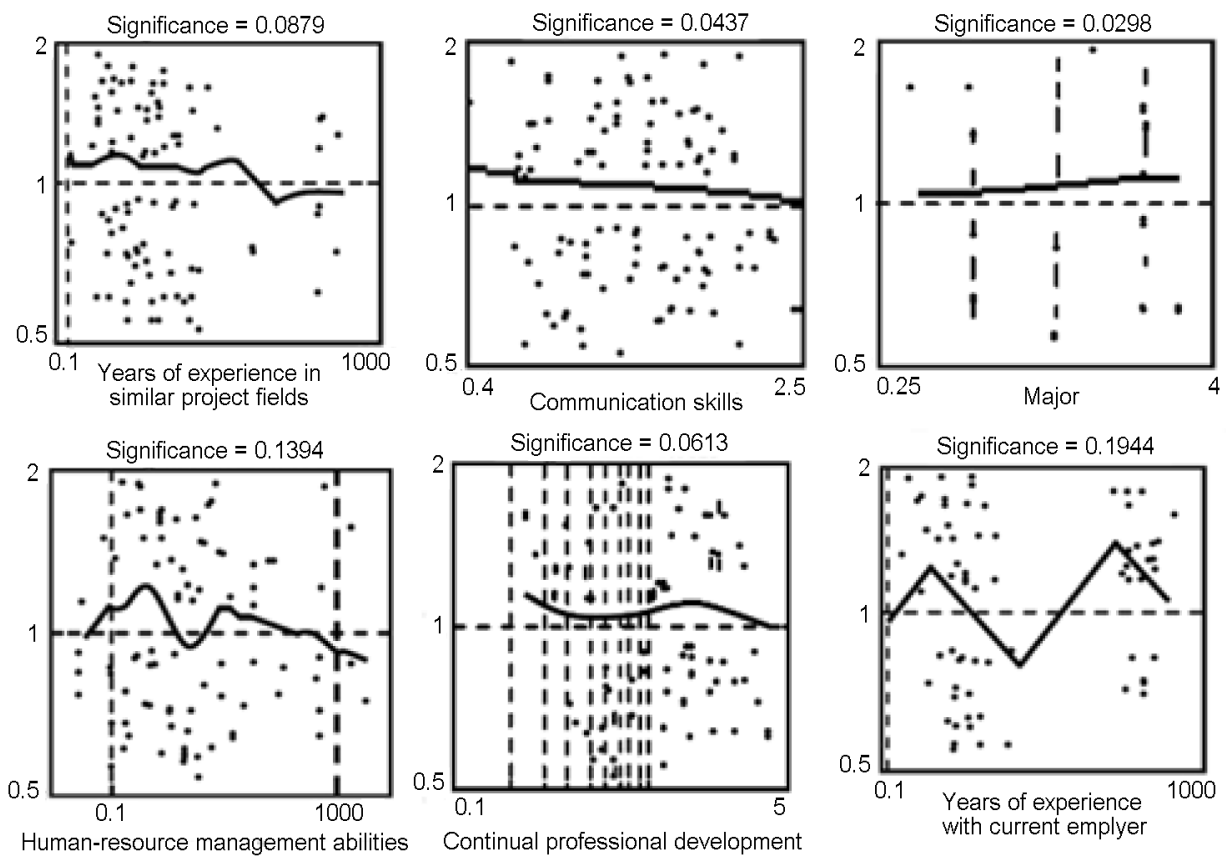

Fig. 3. Samples of fuzzy curves for different criteria

The fuzzy curve for each input variable is plotted by taking $x_{i j}$ on the $x$-axis and the corresponding $c_{j}\left(x_{i}\right)$ on the $y$-axis. The importance of an input variable can be ranked according to the range covered by its corresponding fuzzy curve. If the fuzzy curve for a given input is flat, then this input has little influence on the output data and it is not considered a significant input. Thus, the fuzzy correlation of the $i^{\text {th }}$ input to the output can be found from the difference between the maximum and minimum values of $c_{j}\left(x_{i}\right)$. Accordingly, the importance of the sub-criteria can be determined.

Fig. 3 depicts the fuzzy curves for 6 different subcriteria as sample. Using the fuzzy curves, the significance of the criteria coefficients can be calculated. The results of this calculation are shown in Table 2.

Table 2. Coefficients of importance for different criteria

\begin{tabular}{c|c|c|c}
\hline $\begin{array}{c}\text { Number of } \\
\text { criterion }\end{array}$ & $\mathrm{W}_{\mathrm{j}}$ & $\begin{array}{c}\text { Number of } \\
\text { criterion }\end{array}$ & $\mathrm{W}_{\mathrm{j}}$ \\
\hline 1 & 0.179 & 13 & 0.061 \\
\hline 2 & 0.117 & 14 & 0.192 \\
\hline 3 & 0.194 & 15 & 0.027 \\
\hline 4 & 0.088 & 16 & 0.053 \\
\hline 5 & 0.105 & 17 & 0.035 \\
\hline 6 & 0.105 & 18 & 0.003 \\
\hline 7 & 0.012 & 19 & 0.139 \\
\hline 8 & 0.009 & 20 & 0.044 \\
\hline 9 & 0.03 & 21 & 0.035 \\
\hline 10 & 0.016 & 22 & 0.015 \\
\hline 11 & 0.015 & 23 & 0.005 \\
\hline 12 & 0.023 & & \\
\hline
\end{tabular}

\subsection{Choosing the optimal system}

After identifying the importance coefficients for all criteria, less important criteria (inputs) should be eliminated to obtain a simpler model. Generally, the lower the number of inputs, the greater is the number of model errors. Model errors were therefore defined for different numbers of inputs. This was conducted for different models with different numbers of rules. Furthermore, in order to evaluate the effect of the type of t-norm and t-co-norm, different models with different numbers of outputs, different numbers of fuzzy rules, and different types of norms and co-norms were developed and tested.

In this research, the equation suggested by Filev and Yager (1991) has been used for deffuzification:

$$
\bar{y}=\frac{\int(\mu)^{\alpha} y d y}{\int(\mu)^{\alpha} d y}, \alpha>0,
$$

where: $\mu$ is the degree of membership and $\alpha$ is a coefficient equal to one.

Table 3 shows the number of model errors in the selection of the most suitable candidate in pair-wise comparisons for 100 training data. It is clear that systems with different t-norms and t-co-norms have similar performances with minute differences. This indicates the minor effect of the type of t-norm and t-co-norm on the performance of the system. However, a combination of "algebraic product" and "max" would give optimal results. This combination was therefore used in the final system.

Obviously, the number of fuzzy rules and the number of criteria taken into consideration depend on the accuracy expected from the system.

In this case, a final system with 71 rules and 15 criteria was selected. The number of errors given by this system was 1 among 100 training data; this was considered to be an acceptable error rate. This means that from the initial 23 criteria, 8 were eliminated to simplify the model. The eliminated, less important criteria are: Physical appearance, Being share holder or board member of 
Table 3. Number of errors for different systems in the selection of the most suitable candidate through pair-wise comparisons

\begin{tabular}{|c|c|c|c|c|c|c|c|c|c|c|c|c|c|c|}
\hline & \multicolumn{7}{|c|}{ Min } & \multicolumn{7}{|c|}{ Algebraic product } \\
\hline \multirow{16}{*}{$\stackrel{\Delta}{\Sigma}$} & \multicolumn{7}{|c|}{ Number of rules } & \multicolumn{7}{|c|}{ Number of rules } \\
\hline & \multirow{15}{*}{ 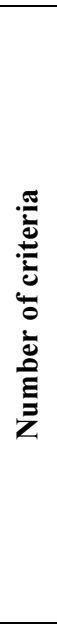 } & & 71 & 62 & 52 & 48 & 43 & \multirow{15}{*}{ 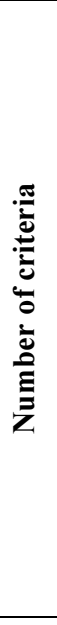 } & & 71 & 62 & 52 & 48 & 43 \\
\hline & & 10 & 2 & 3 & 4 & 5 & 5 & & 10 & 2 & 3 & 3 & 4 & 5 \\
\hline & & 11 & 2 & 2 & 3 & 4 & 5 & & 11 & 2 & 2 & 3 & 4 & 4 \\
\hline & & 12 & 2 & 2 & 3 & 3 & 5 & & 12 & 2 & 2 & 2 & 3 & 4 \\
\hline & & 13 & 2 & 2 & 2 & 3 & 4 & & 13 & 2 & 2 & 2 & 3 & 4 \\
\hline & & 14 & 2 & 2 & 2 & 3 & 4 & & 14 & 2 & 2 & 2 & 2 & 4 \\
\hline & & 15 & 2 & 2 & 2 & 3 & 3 & & 15 & 1 & 2 & 2 & 2 & 3 \\
\hline & & 16 & 1 & 2 & 2 & 3 & 3 & & 16 & 1 & 1 & 2 & 2 & 2 \\
\hline & & 17 & 1 & 2 & 2 & 3 & 3 & & 17 & 1 & 1 & 1 & 2 & 2 \\
\hline & & 18 & 1 & 2 & 2 & 3 & 3 & & 18 & 1 & 1 & 1 & 2 & 2 \\
\hline & & 19 & 1 & 2 & 2 & 2 & 3 & & 19 & 1 & 1 & 1 & 1 & 1 \\
\hline & & 20 & 0 & 1 & 1 & 2 & 3 & & 20 & 1 & 1 & 1 & 1 & 1 \\
\hline & & 21 & 0 & 0 & 1 & 2 & 3 & & 21 & 1 & 1 & 1 & 1 & 1 \\
\hline & & 22 & 0 & 0 & 0 & 2 & 2 & & 22 & 0 & 0 & 0 & 0 & 1 \\
\hline & & 23 & 0 & 0 & 0 & 1 & 1 & & 23 & 0 & 0 & 0 & 0 & 1 \\
\hline \multirow{16}{*}{ 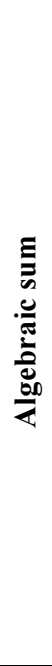 } & \multicolumn{7}{|c|}{ Number of rules } & \multicolumn{7}{|c|}{ Number of rules } \\
\hline & \multirow{15}{*}{ 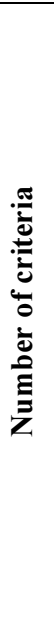 } & & 71 & 62 & 52 & 48 & 43 & \multirow{15}{*}{ 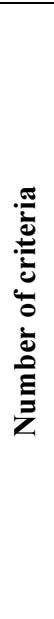 } & & 71 & 62 & 52 & 48 & 43 \\
\hline & & 10 & 3 & 3 & 5 & 5 & 5 & & 10 & 3 & 3 & 4 & 5 & 5 \\
\hline & & 11 & 3 & 3 & 4 & 4 & 5 & & 11 & 3 & 3 & 3 & 3 & 5 \\
\hline & & 12 & 3 & 3 & 3 & 4 & 5 & & 12 & 2 & 3 & 3 & 3 & 4 \\
\hline & & 13 & 2 & 2 & 3 & 4 & 5 & & 13 & 2 & 3 & 3 & 3 & 4 \\
\hline & & 14 & 2 & 2 & 2 & 3 & 4 & & 14 & 2 & 3 & 3 & 3 & 3 \\
\hline & & 15 & 2 & 2 & 2 & 3 & 4 & & 15 & 2 & 2 & 2 & 2 & 3 \\
\hline & & 16 & 2 & 2 & 2 & 3 & 3 & & 16 & 1 & 2 & 2 & 2 & 2 \\
\hline & & 17 & 2 & 2 & 2 & 2 & 2 & & 17 & 1 & 1 & 1 & 1 & 2 \\
\hline & & 18 & 1 & 1 & 1 & 1 & 2 & & 18 & 1 & 1 & 1 & 1 & 2 \\
\hline & & 19 & 1 & 1 & 1 & 1 & 2 & & 19 & 1 & 1 & 1 & 1 & 2 \\
\hline & & 20 & 1 & 1 & 1 & 1 & 1 & & 20 & 1 & 0 & 0 & 1 & 1 \\
\hline & & 21 & 0 & 0 & 1 & 1 & 1 & & 21 & 0 & 0 & 0 & 0 & 1 \\
\hline & & 22 & 0 & 0 & 0 & 1 & 1 & & 22 & 0 & 0 & 0 & 0 & 1 \\
\hline & & 23 & 0 & 0 & 0 & 1 & 1 & & 23 & 0 & 0 & 0 & 1 & 1 \\
\hline
\end{tabular}

the company, Quality assessment of previous projects, Degree, Quality of the university where the applicant graduated, Specialization, Work performance and Project condition assessment and prediction.

\section{Validation of the fuzzy system for selection of project manager}

To evaluate the developed fuzzy model, the interviews conducted for the selection of a project manager were reviewed. As mentioned before, 62 data from the available dataset were considered. The model is expected to be sufficiently accurate to rank the participants in the interviews correctly. The results of this evaluation are presented in Fig. 4.

In the figure, the empty circles indicate the model responses and the filled circles indicate the desired responses. As can be seen, the model contains only one error in the pair-wise comparisons of participants (data item number 18). In the other 61 cases, the model responses and the desired responses are slightly larger or smaller than 1; in other words, in almost all pair-wise comparisons between the candidates, the most suitable candidate is determined correctly. This indicates the model's potential to predict the right output, that is, the best candidate for the position of project manager.

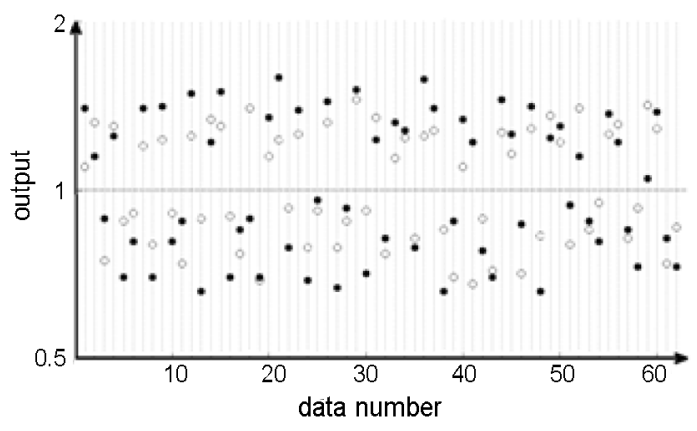

Fig. 4. Results of the evaluation of the model developed for selecting a project manager

\section{Case study}

To show how our model performs under real-world conditions, it was used in real interviews conducted by the senior managers of a major construction company. These interviews were conducted with seven candidates. The 
candidates' scores in each criterion, as well as their overall scores determined on the basis of the interviewers' opinions, are shown in Table 4.

On the basis of the accumulated information in Table 4, pair-wise comparisons between candidates were performed using the new fuzzy system based on 15 criteria. The results obtained from the system and the actual results determined by the interviewers are summarized in Table 5 .

As can be observed, the pair-wise comparisons were performed correctly, except in two cases. These two cases are the comparisons between the $4^{\text {th }}$ and $6^{\text {th }}$ pair of candidates and the $7^{\text {th }}$ and $3^{\text {rd }}$ pair (these two cases are highlighted in bold).

For these interviews, using the proposed system with 15 criteria, the required time to input the information for seven candidates and run the fuzzy system is less than
20 minutes. When using the old fuzzy system with all 23 criteria, the total time required is more than twice this 40 minutes. In addition, gathering the information for 15 criteria is much faster and easier. Therefore, when there are a large number of candidates, the current system is recommended.

If a normal traditional interview takes 30 minutes, interviewing all seven candidates would require 210 mins. This comparison clearly indicates the advantage of using a fuzzy system with respect to the time needed. It is important to mention that to use the fuzzy model, we need to gather the candidates' information, which is a time-consuming task. However, this is not the duty of senior managers, and other staff could collect such data. Therefore, this time could be eliminated from the time required to run the model.

Table 4. Interviewees' information: comparisons of real-life interviews and fuzzy system cases

\begin{tabular}{|c|c|c|c|c|c|c|c|c|c|}
\hline No. & Criterion & Status & 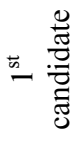 & 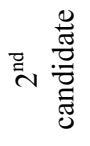 & 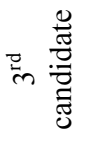 & 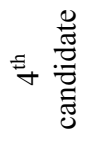 & 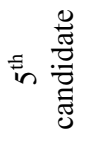 & E & 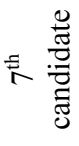 \\
\hline 1 & Years of experience & $0-45$ years & 27 & 21 & 12 & 9 & 28 & 14 & 9 \\
\hline 2 & Years of management experience & $0-45$ years & 24 & 8 & 5 & 4 & 18 & 5 & 0 \\
\hline 3 & Years of experience with current employer & $0-45$ years & 22 & 8 & 0 & 0 & 12 & 5 & 0 \\
\hline 4 & Years of experience in similar project fields & $0-45$ years & 27 & 21 & 8 & 5 & 15 & 5 & 6 \\
\hline 5 & $\begin{array}{l}\text { Years of experience working with project } \\
\text { owner }\end{array}$ & $0-45$ years & 0 & 5 & 0 & 0 & 6 & 9 & 0 \\
\hline 6 & $\begin{array}{l}\text { Years of experience in similar project } \\
\text { environments }\end{array}$ & $0-45$ years & 5 & 15 & 4 & 4 & 15 & 5 & 3 \\
\hline 7 & Major & $\begin{array}{l}\text { Mechanical Engineering } \\
\text { Civil Engineering } \\
\text { Chemical Engineering } \\
\text { Electrical Engineering } \\
\text { Other }\end{array}$ & 4 & 3 & 4 & 4 & 4 & 4 & 3 \\
\hline 8 & Continuing professional development & $0-200 \mathrm{~h}$ & 70 & 110 & 90 & 40 & 80 & 150 & 50 \\
\hline 9 & General communication skills in English & $0-100$ score & 85 & 80 & 55 & 55 & 85 & 70 & 65 \\
\hline 10 & Gender & $\begin{array}{l}\text { Male (1) } \\
\text { Female (2) }\end{array}$ & 1 & 1 & 1 & 1 & 1 & 1 & 1 \\
\hline 11 & Age & $25-70$ & 55 & 55 & 45 & 35 & 54 & 38 & 24 \\
\hline 12 & Physical and mental abilities & $\begin{array}{l}\text { Healthy (1), } \\
\text { Unhealthy (2) }\end{array}$ & 1 & 1 & 1 & 1 & 1 & 1 & 2 \\
\hline 13 & $\begin{array}{l}\text { Human resource management abilities } \\
\text { (number of employees working under } \\
\text { applicant's supervision) }\end{array}$ & $0-500$ persons & 100 & 80 & 30 & 40 & 450 & 200 & 10 \\
\hline 14 & Communication skills & $0-100$ score & 85 & 35 & 60 & 55 & 90 & 70 & 70 \\
\hline \multirow[t]{2}{*}{15} & Sound decision-making under pressure & $0-100$ score & 75 & 65 & 65 & 60 & 80 & 80 & 55 \\
\hline & Final score & $0-100$ score & 90 & 85 & 62 & 75 & 70 & 65 & 55 \\
\hline
\end{tabular}

Table 5. Comparison of candidates: real results vs. model results

\begin{tabular}{l|c|c|c|c|c|c|c|c|c|c|c|c|c|c}
\hline Comparison between candidates & $1^{\text {st }} / 2^{\text {nd }}$ & $1 / 3$ & $1 / 4$ & $1 / 5$ & $1 / 6$ & $1 / 7$ & $2 / 1$ & $2 / 3$ & $2 / 4$ & $2 / 5$ & $2 / 6$ & $2 / 7$ & $3 / 1$ & $3 / 2$ \\
\hline Model's output & 1.2 & 1.4 & 1.3 & 1.2 & 1.6 & 1.3 & 0.7 & 1.1 & 1.4 & 1.1 & 1.6 & 1.2 & 0.9 & 0.9 \\
\hline Real output & 1.1 & 1.5 & 1.2 & 1.3 & 1.4 & 1.6 & 0.9 & 1.4 & 1.1 & 1.2 & 1.3 & 1.5 & 0.7 & 0.7 \\
\hline Comparison between candidates & $3 / 4$ & $3 / 5$ & $3 / 6$ & $3 / 7$ & $4 / 1$ & $4 / 2$ & $4 / 3$ & $4 / 5$ & $4 / 6$ & $4 / 7$ & $5 / 1$ & $5 / 2$ & $5 / 3$ & $5 / 4$ \\
\hline Model's output & 0.7 & 0.8 & 0.6 & 1.3 & 0.7 & 0.7 & 1.4 & 1.4 & 1.3 & 1.1 & 0.6 & 0.7 & 1.2 & 0.7 \\
\hline Real output & 0.8 & 0.9 & 0.9 & 1.1 & 0.8 & 0.9 & 1.2 & 1.1 & 1.2 & 1.4 & 0.8 & 0.8 & 1.1 & 0.9 \\
\hline Comparison between candidates & $5 / 6$ & $5 / 7$ & $6 / 1$ & $6 / 2$ & $6 / 3$ & $\mathbf{6 / 4}$ & $6 / 5$ & $6 / 7$ & $7 / 1$ & $7 / 2$ & $7 / 3$ & $7 / 4$ & $7 / 5$ & $7 / 6$ \\
\hline Model's output & 1.3 & 1.4 & 0.6 & 0.9 & 1.3 & $\mathbf{1 . 1}$ & 0.7 & 1.1 & 0.7 & 0.8 & $\mathbf{1 . 1}$ & 0.7 & 0.7 & 0.9 \\
\hline Real output & 1.1 & 1.3 & 0.7 & 0.8 & 1.1 & $\mathbf{0 . 9}$ & 0.9 & 1.2 & 0.6 & 0.6 & $\mathbf{0 . 9}$ & 0.7 & 0.8 & 0.8 \\
\hline
\end{tabular}




\section{Conclusions and discussion}

The selection of a project manager from a set of potential candidates is an important, difficult, and time-consuming task for the senior managers of any construction company. This problem worsens with an increase in the number of candidates. There is also a risk of human error in judgment and decision making. On the other hand, not interviewing all the candidates may mean overlooking some qualified applicants. There is therefore a need for computational models that can increase the accuracy of decisions and reduce the time required.

Previously, the authors constructed a fuzzy system for the process of project manger selection in construction firms. This fuzzy system needs information for 23 criteria. Gathering the information from a large number of candidates for all 23 criteria is difficult and time consuming. Therefore, in this paper, a more robust fuzzy system is proposed to solve this problem. To perform accurately, the proposed system only needs information for 15 of the more important criteria. This helps to speed up the selection procedure significantly. The proposed model was developed on the basis of data accumulated from a number of interviews conducted in a number of major construction firms. The results obtained using the proposed model in real interviews show the model's ability to predict accurate outputs and its ability to reduce the time required for gathering data and running the system.

Unfortunately, although there are several existing studies, the application of decision-support systems in the construction industry is still in its initial stages. In our case, several factors that are difficult to take account of in the model-building process could affect the performance of the fuzzy model. For example, it is difficult to allow for psychological factors in the evaluation process. It might not always be possible to interview candidates extensively. There might be differences between internal and external candidates that must be accounted for. Finally, we still seem to lack good outcome data that can help us understand whether or not a choice that we make turns out to be a good one. Considering the limitations, the authors suggest using this model in two-stage interviews as follows:

- In the first stage, a limited number of candidates are selected;

- In the next stage, the chosen candidates are interviewed routinely and the most suitable one is selected by the interviewer.

In future studies, the authors intend to expand the current fuzzy system to a general model that can be used as a tool to assist in a vast range of interviews conducted in construction companies and other related firms.

\section{References}

Antonelli, M.; Ducange, P.; Lazzerini, B.; Marcelloni, F. 2009. Learning concurrently partition granularities and rule bases of Mamdani fuzzy systems in a multi-objective evolutionary framework, International Journal of Approximate Reasoning 50(7): 1066-1080.

http://dx.doi.org/10.1016/j.ijar.2009.04.004
Berger, L. 1996. Emerging role of management in civil engineering, Journal of Management in Engineering ASCE 12(4): 37-39.

http://dx.doi.org/10.1061/(ASCE)0742-597X(1996)12:4(37)

Castellano, G.; Fanelli, A. M.; Gentile, E.; Roselli, T. 2002. A GA-based approach to optimization of fuzzy models learned from data, in GECCO 2002 Program, New York, 5-8.

Chao, C. T.; Chen, Y. J.; Teng, C. C. 1996. Simplification of fuzzy-neural systems using similarity analysis, IEEE Transaction on Systems, Man, and Cybernetics, Part B: Cybernetics 26(2): 344-354.

http://dx.doi.org/10.1109/3477.485887

Chaturvedi, K. T.; Pandit, M.; Srivastava, L.; Sharma, J.; Bhatele, R. P. 2009. Hybrid fuzzy-neural network based composite contingency ranking employing fuzzy curves for feature selection, Neurocomputing 73(1-3): 506-516. http://dx.doi.org/10.1016/j.neucom.2009.06.012

De Baets, B.; Janssens, S.; De Meyer, H. 2009. On the transitivity of a parametric family of cardinality-based similarity measures, International Journal of Approximate Reasoning 50(1): 104-116. http://dx.doi.org/10.1016/j.ijar.2008.03.006

Dolfi, J.; Andrews, E. J. 2007. The subliminal characteristics of project managers: an exploratory study of optimism overcoming challenge in the project management work environment, International Journal of Project Management 25(7): 674-682. http://dx.doi.org/10.1016/j.ijproman.2007.02.002

Du, X.; Zhang, N.; Ying, H. 2008. Structure analysis and system design for a class of Mamdani fuzzy controllers, International Journal of General Systems 37(1): 83-101. http://dx.doi.org/10.1080/03081070701500067

Dubois, D.; Prade, H.; Ughetto, L. 1997. Checking the coherence and redundancy of fuzzy knowledge bases, IEEE Transaction on Fuzzy Systems 5(3): 398-417. http://dx.doi.org/10.1109/91.618276

Eftekhari, M.; Katebi, S. D.; Karimi, M.; Jahanmiri, A. H. 2008. Eliciting transparent fuzzy model using differential evolution, Applied Soft Computing 8(1): 466-476. http://dx.doi.org/10.1016/j.asoc.2007.02.008

Filev, D. P.; Yager, R. R. 1991. A generalized defuzzification method under BAD distribution, International Journal of Intelligent Systems 6(7): 687-697. http://dx.doi.org/10.1002/int.4550060702

Goodwin, R. S. C. 1993. Skills required of effective project managers, Journal of Management in Engineering ASCE 9(3): 217-226. http://dx.doi.org/10.1061/(ASCE)9742597X(1993)9:3(217)

Guillaume, S. 2001. Designing fuzzy inference systems from data: an interpretability oriented review, IEEE Transaction on Fuzzy Systems 9(3): 426-443. http://dx.doi.org/10.1109/91.928739

Ishibushi, H.; Nakashima, T.; Murata, T. 2001. Three-objective genetics-based machine learning for linguistic rule extraction, Information Sciences 136(1-4): 109-133. http://dx.doi.org/10.1016/S0020-0255(01)00144-X

Jin, Y.; von Seelen, W.; Sendhoff, B. 1999. On generating FC3 fuzzy rule systems from data using evolution strategies, IEEE Transaction on Systems, Man, and Cybernetics, Part B: Cybernetics 29(6): 829-845. http://dx.doi.org/10.1109/3477.809036

Jin, Y. 2000. Fuzzy modeling of high-dimensional systems: complexity reduction and interpretability improvement, 
IEEE Transaction on Fuzzy Systems 8(2): 212-221. http://dx.doi.org/10.1109/91.842154

Karaboga, D.; Bagis, A.; Haktanir, T. 2008. Controlling spillway gates of dams by using fuzzy logic controller with optimum rule number, Applied Soft Computing 8(1): 232-238. http://dx.doi.org/10.1016/j.asoc.2007.01.004

Lee, C.-H.; Pan, Y.-H. 2009. Performance enhancement for neural fuzzy systems using asymmetric membership functions, Fuzzy Sets and Systems 160(7): 949-971. http://dx.doi.org/10.1016/j.fss.2008.09.007

Liang, X.; Pedrycz, W. 2009. Logic-based fuzzy networks: a study in system modeling with triangular norms and uninorms, Fuzzy Sets and Systems 160(24): 3475-3502. http://dx.doi.org/10.1016/j.fss.2009.04.014

Liao, S. 2007. Top ten qualities of project manager heroes: an interview with David B. Perini, Journal of Leadership and Management in Engineering 7(2): 50-60. http://dx.doi.org/10.1061/(ASCE)1532-6748(2007)7:2(50)

Meredith, J. R.; Samuel, J.; Mantel, Jr. 1995. Project management: a managerial approach. 3rd ed. New York: John Wiley. $608 \mathrm{p}$.

Ogunlana, S.; Siddiqui, Z.; Yisa, S.; Olomolaiye, P. 2002. Factors and procedures used in matching project managers to construction projects in Bangkok, International Journal of Project Management 20(5): 385-400. http://dx.doi.org/10.1016/S0263-7863(01)00017-5

Paiva, R. P.; Dourado, A. 2004. Interpretability and learning in neuro-fuzzy systems, Fuzzy Sets and Systems 147(1): 1738. http://dx.doi.org/10.1016/j.fss.2003.11.012

Pheng, L. S.; Chuan, Q. T. 2006. Environmental factors and work performance of project managers in the construction industry, International Journal of Project Management 24(1): 24-37.

http://dx.doi.org/10.1016/j.ijproman.2005.06.001

Plebankiewicz, E. 2009. Contractor prequalification model using fuzzy sets, Journal of Civil Engineering and Management 15(4): 377-385.

http://dx.doi.org/10.3846/1392-3730.2009.15.377-385
Radziszewska-Zielina, E. 2011. Fuzzy control of partnering relations of a construction enterprise, Journal of Civil Engineering and Management 17(1): 5-15. http://dx.doi.org/10.3846/13923730.2011.554172

Rashidi, A.; Jazebi, F.; Brilakis, I. 2011. Neuro-fuzzy genetic system for selection of construction project managers, Journal of Construction Engineering and Management ASCE 137(1): 17-29.

http://dx.doi.org/10.1061/(ASCE)CO.1943-7862.0000200

Setnes, M.; Babuska, R.; van Nauta Lemke, H. R. 1998. Similarity measures in fuzzy rule base simplification, IEEE Transaction on Systems, Man, and Cybernetics, Part B: Cybernetics 28(3): 376-386. http://dx.doi.org/10.1109/3477.678632

Sunindijo, R. Y.; Hadikusumo, B. H. W.; Ogunlana, S. 2007. Emotional intelligence and leadership styles in construction project management, Journal of Management in Engineering ASCE 23(4): 166-170.

http://dx.doi.org/10.1061/(ASCE)0742-597X(2007)23:4(166)

Torfi, F.; Rashidi, A. 2011. Selection of project managers in construction firms using AHP and Fuzzy TOPSIS: a case study, Journal of Construction in Developing Countries 16(1): 69-89.

Torno, S.; Toraño, J.; Menéndez, M.; Gent, M.; Velasco, J. 2011. Mathematical and fuzzy logic models in prediction of geological and geomechanical properties of rock mass by excavation data on underground works, Journal of Civil Engineering and Management 17(2): 197-206.

Wang, H.; Kwong, S.; Jin, Y.; Wei, W.; Man, K. F. 2005. Multi-objective hierarchical genetic algorithm for interpretable fuzzy rule-based knowledge extraction, Fuzzy Sets and Systems 149(1): 149-186.

http://dx.doi.org/10.1016/j.fss.2004.07.013

Fateme JAZEBI. Lecturer at Payame Noor University, Ahvaz, Iran. She received her Master's degree in Construction Engineering and Management from Amirkabir University of Technology, Tehran, Iran. Her research focuses on the fuzzy theory and it's applications in the project management domain.

Abbas RASHIDI. PhD student and research assistant at the Construction Information Technology Lab (CITL), Georgia Institute of Technology, USA. Prior to joining CITL, he worked as a lecturer at the Department of Civil Engineering, Islamic Azad University, Semnan, Iran. His main research interests include applications of information technologies and computing methods for automating different processes in the construction industry. 